\title{
ACE-inhibitors: a preventive measure for bone flap resorption after autologous cranioplasty?
}

\author{
*Alessa Schütz, MD, ${ }^{1}$ Michael Murek, MD,, Lennart Henning Stieglitz, MD, ${ }^{1}$ \\ Corrado Bernasconi, MD, PhD, ${ }^{3}$ Sonja Vulcu, MD, ${ }^{1}$ Jürgen Beck, MD, ${ }^{1}$ Andreas Raabe, MD, ${ }^{1}$ and \\ Philippe Schucht, MD1
}

Departments of ${ }^{1}$ Neurosurgery and ${ }^{3}$ Neurology, Inselspital, Bern University Hospital, University of Bern, Switzerland; and ${ }^{2}$ Department of Neurosurgery, Zurich University Hospital, Zurich, Switzerland

\begin{abstract}
OBJECTIVE Decompressive craniectomy (DC) is an established treatment for refractory intracranial hypertension. It is usually followed by autologous cranioplasty $(A C)$, the reinsertion of a patient's explanted bone flap. A frequent long-term complication of $A C$ is bone flap resorption (BFR), which results in disfigurement as well as loss of the protective covering of the brain. This study investigates risk factors for BFR after AC, including medical conditions and antihypertensive drug therapies, with a focus on angiotensin-converting enzyme inhibitors (ACEIs), which have been associated with a beneficial effect on bone healing and bone preservation in orthopedic, osteoporosis, and endocrinology research.
\end{abstract}

METHODS In this single-center, retrospective study 183 consecutive cases were evaluated for bone flap resorption after AC. Information on patient demographics, medical conditions, antihypertensive therapy, and BFR_defined as an indication for revision surgery established by a neurosurgeon based on clinical or radiographic assessments-was collected. A Kaplan-Meier analysis of time from AC to diagnosis of BFR was performed, and factors associated with BFR were investigated using the log-rank test and Cox regression.

RESULTS A total of 158 patients were considered eligible for inclusion in the data analysis. The median follow-up time for this group was 2.2 years $(95 \% \mathrm{Cl} 1.9-2.5$ years). BFR occurred in 47 patients (29.7\%), with a median time to event of 3.7 years (95\% Cl 3.3-4.1 years). An ACEl prescription was recorded in 57 cases (36.1\%). Univariate Kaplan-Meier analysis and the log-rank test revealed that ACEI therapy (2-year event free probability [EFP] 83.8\% $\pm 6.1 \%$ standard error vs $63.9 \% \pm 5.6 \%, p=0.02$ ) and ventriculoperitoneal (VP) shunt treatment (2-year EFP $86.9 \% \pm 7.1 \%$ vs $66 \% \pm 5.0 \%$, $p=0.024)$ were associated with a lower probability of BFR. Multiple Cox regression analysis showed ACEI therapy (HR $0.29, p=0.012)$, VP shunt treatment (HR 0.278, $p=0.009$ ), and male sex (HR 0.500, $p=0.040$ ) to be associated with a lower risk for BFR, whereas bone fragmentation (HR 1.92, $p=0.031$ ) was associated with a higher risk for BFR.

CONCLUSIONS Hypertensive patients treated with ACEls demonstrate a lower rate of BFR than patients treated with other hypertensive medications and nonhypertensive patients. Our results are in line with previous reports on the positive influence of ACEls on bone healing and preservation. Further analysis of the association between ACEI treatment and BFR development is needed and will be evaluated in a multicenter prospective trial.

https://thejns.org/doi/abs/10.3171/2018.6.JNS172605

KEYWORDS bone flap resorption; aseptic osteolysis; craniectomy; autologous cranioplasty; ACE-inhibitors; bone preservation; surgical technique

$\mathrm{D}$ ECOMPRESSIVE craniectomy (DC) is a well-established neurosurgical procedure in the treatment of refractory intracranial hypertension. Although DC is highly effective and generally regarded as a lifesaving procedure, it remains an invasive surgery with an elevated risk for complications. ${ }^{18}$ To restore the bony coverage of the brain and avoid clinical impairments like the "syndrome of the trephined," 3 DC is usually followed by a second surgery to cover the defect once the brain swelling has regressed. Many options exist as to the timing and

ABBREVIATIONS AC = autologous cranioplasty; $\mathrm{ACEI}=$ angiotensin-converting enzyme inhibitor; $\mathrm{BFR}=$ bone flap resorption; $\mathrm{Cl}=\mathrm{confidence} \mathrm{interval;} \mathrm{CVI}=\mathrm{cerebro-}$ vascular ischemia; $\mathrm{DC}=$ decompressive craniectomy; EFP = event-free probability; HR = hazard ratio; ICH = intracerebral hemorrhage; IQR = interquartile range; $\mathrm{mTTE}$ = median time to event; $\mathrm{PTH}=$ parathyroid hormone; $\mathrm{RAAS}=$ renin-angiotensin-aldosterone system; $\mathrm{RR}=$ relative risk; $\mathrm{SAH}=\mathrm{subarachnoid} \mathrm{hemorrhage;} \mathrm{TBI}=$ traumatic brain injury; VP = ventriculoperitoneal.

SUBMITTED November 29, 2017. ACCEPTED June 11, 2018

INCLUDE WHEN CITING Published online November 23, 2018; DOI: 10.3171/2018.6.JNS172605.

${ }^{*}$ A.S. and M.M. contributed equally to this work and share first authorship. 
procedure for covering the bony defect, ${ }^{10,27}$ but autologous cranioplasty (AC) - the reinsertion of the explanted, cryoconserved bone flap-is the most common one. ${ }^{10}$

A frequently observed long-term complication of $\mathrm{AC}$ is bone flap resorption (BFR), an aseptic, osteolytic process leading to significant disintegration of the reimplanted bone in up to $54.4 \%$ of pediatric patients ${ }^{4,21,25}$ and up to $30.4 \%$ of patients in mixed cohorts. . $^{5,8,9,17,22,35} \mathrm{BFR}$ can lead to visible and palpable, aesthetically disfiguring defects, and in its advanced form it results in a loss of the bony coverage of the brain. Revision surgery with implantation of a synthetic bone flap is required in severe cases of BFR.

In recent decades there has been a growing interest in identification of potential strategies for lowering BFR rates, avoiding revision surgery, and preventing possible surgical complications. Previous studies have found risk factors such as fragmentation of the bone flap, ${ }^{5,8,21,33}$ younger age,,$^{4,5,821}$ longer time between DC and AC,, 33 ventriculoperitoneal (VP) shunt implantation, ${ }^{4,22}$ and larger bone flap size ${ }^{32}$ to be associated with higher rates of BFR. The pathophysiological mechanism of BFR, however, remains unclear, and no preventive measures have been identified to date.

In addition, research in the fields of orthopedics, osteoporosis, and endocrinology has identified a beneficial effect of angiotensin-converting enzyme inhibitors (ACEIs) on bone preservation and bone healing. These medications have been found to be associated with an increased bone mineral density, ${ }^{26}$ improved osteoporosis, ${ }^{34}$ and bone healing, ${ }^{39}$ as well as reduced fracture risk. ${ }^{28,31}$ They prevent the conversion of angiotensin I into angiotensin II, which increases calcium metabolism and activates osteoclasts responsible for bone resorption. ${ }^{34}$ To verify whether these findings could be applied to autologous bone flaps we set out to investigate a putative effect of ACEIs on BFR development.

\section{Methods}

\section{Study Design and Patient Cohort}

We performed a single-center, retrospective analysis of 183 consecutive cases in which patients received AC after DC at the Department of Neurosurgery, Inselspital, University Hospital Bern, Switzerland, between June 2003 and August 2015. Data were collected and managed using REDCap, a secure, web-based electronic data capture tool $^{15}$ in a retrospective review of hospital records and CT scans. Patients with DC, followed by primary implantation of the autologous bone flap (AC) were included in the study. Patients who did not show up for at least 1 follow-up visit or never received a follow-up CT scan were considered ineligible and were excluded from the analysis. Subjects who received a synthetic bone flap within 1 year after $\mathrm{AC}$ for reasons other than BFR were also excluded from the study.

Institutional protocol required a postoperative followup visit with CT scan 6 weeks after surgery. Further follow-up visits were scheduled depending on the clinical or radiographic findings of the initial follow-up or if requested by the patient or his or her family practitioner.
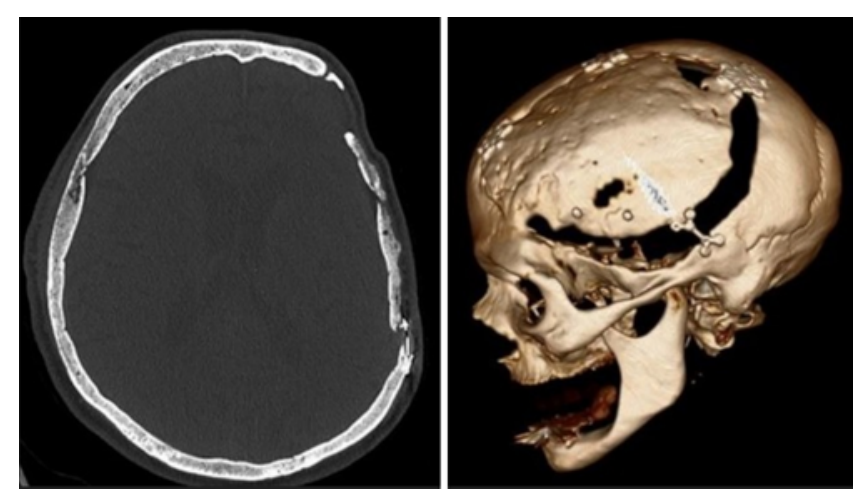

FIG. 1. Left: CT scan showing BFR 4.9 years after bone flap reimplantation. Right: 3D CT reconstruction of skull with BFR (same case).

The last point of follow-up was defined as the date of BFR diagnosis by clinical or radiographic examination. For patients with no documented BFR, the clinical results of the most recent follow-up visit or available CT scan defined the follow-up time.

\section{Definition of Bone Flap Resorption}

Bone flap resorption (BFR) was defined at the point of necessity of surgical revision, as diagnosed after a clinical examination or viewing of CT scans by the treating neurosurgeon (Fig. 1).

Bone flap size was estimated using the maximum anteroposterior (B) and craniocaudal diameters (b) from lateral scout images with the formula $\mathrm{A}=\pi / 4 \times \mathrm{B} \times \mathrm{b}$, as proposed by Dünisch et al. ${ }^{8}$ and Ewald et al. ${ }^{9}$

\section{Decompressive Craniectomy}

DC was performed according to a previously published protocol ${ }^{14}$ with the cross midline skin incision technique to facilitate cranioplasty and a DC diameter of at least 150 $\mathrm{mm}$. The dura was opened in a stellate form, folded back on the exposed brain, and covered with a layer of Surgicel (Ethicon, Inc.). The explanted, sterile bone flap was cryoconserved at $-80^{\circ} \mathrm{C}$.

\section{Autologous Cranioplasty}

The sterile, cryoconserved bone flaps were thawed for reimplantation at room temperature. In 21 (13.3\%) patients multiple 1-mm-diameter holes were drilled into the bone flap in order to prevent the build-up of epidural fluid collections in combination with a subcutaneous drainage. The number of holes drilled was determined according to the individual neurosurgeon's preference and ranged between 3 and 52 per bone flap (mean 8 holes). Meticulous dissection of the myocutaneous flap and exposure of bony margins followed. The bone flap fixation method-i.e., titanium plates and screws (low profile, Synthes), titanium clamps (Craniofix, Braun Medical AG), or cranial sutures (nonabsorbable Surgilon braided nylon, Covidien) -was based on the neurosurgeon's preference.

\section{Recorded Variables}

The following variables were extracted from clinical 


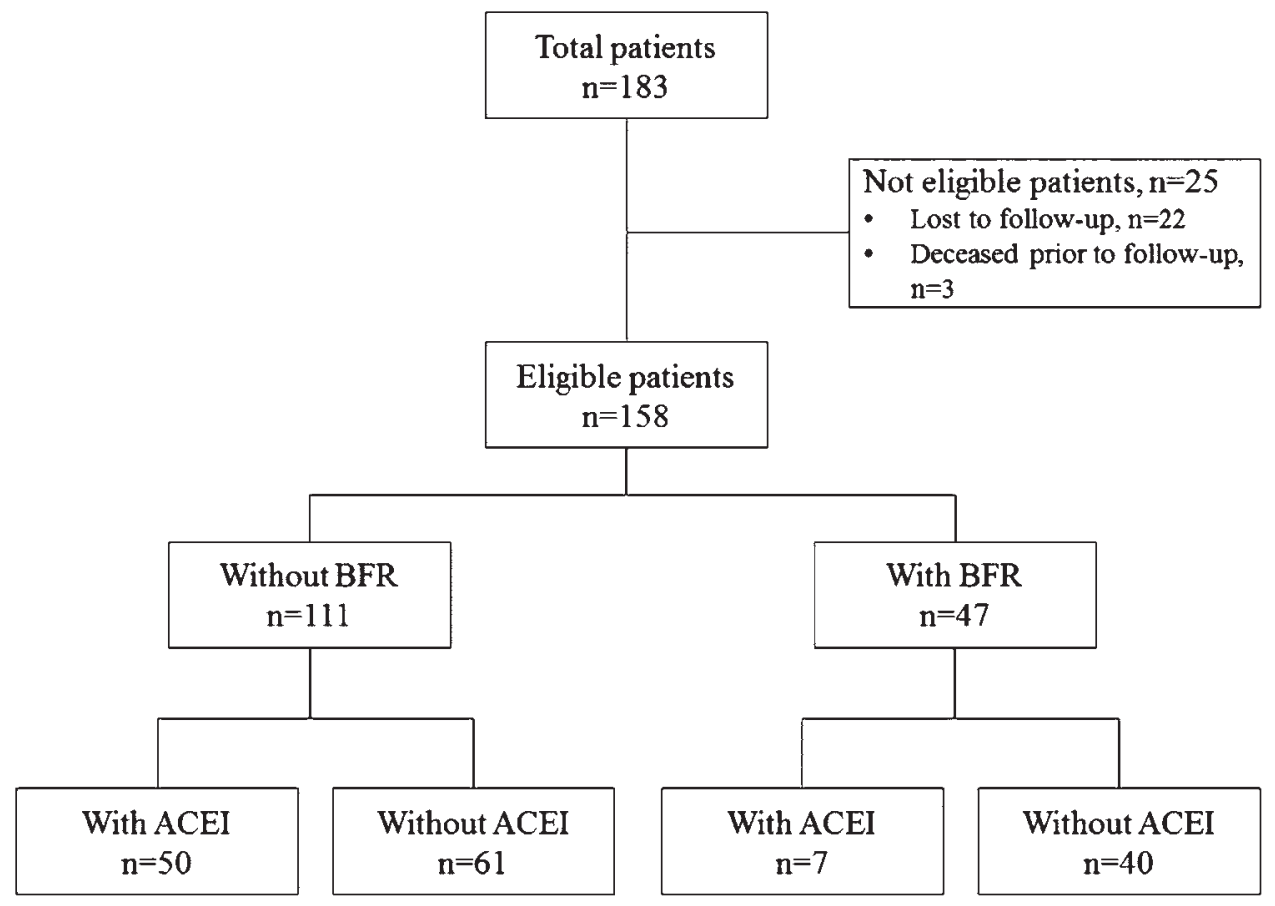

FIG. 2. Flowchart showing development of BFR in patients with or without antihypertensive therapy with ACEls.

records and entered into our database: patient sex, age, admission diagnosis leading to DC, dates of surgery (including $\mathrm{DC}$ and $\mathrm{AC}$ ), number of bone fragments and size, $\mathrm{VP}$ shunt placement, diagnosis of arterial hypertension and diabetes, nicotine consumption, antihypertensive therapy with ACEIs, and the date of the last follow-up visit. The presence of BFR was documented in clinical records based on clinical evaluation or after evaluation of CT scans.

Patients who declined revision surgery despite an indication as determined by the treating neurosurgeon were included in the study and categorized as patients with BFR.

\section{Statistical Analysis}

Baseline characteristics of patients with and without BFR were analyzed descriptively and compared using the 2-sample t-test with pooled variances for continuous variables and Fisher's exact test for categorical variables. A Kaplan-Meier analysis of time from AC to diagnosis of BFR was performed and putative predictors associated with BFR were investigated using the log-rank test. A multivariable Cox proportional hazards model was fitted to delineate the specific influence of ACEI on BFR after accounting for previously mentioned predictors. Median follow-up time and results in the time-to-event analysis were presented and compared as median time-to-event (mTTE) calculated using the reversed Kaplan-Meier estimate $^{30}$ and 2-year event-free probabilities (EFPs). Results from Cox regression analysis were presented with hazard ratios (HRs) and 95\% confidence intervals (CIs). Patients missing data on any of the predictors and patients without follow-up were excluded from the analysis. To avoid unnecessary radiation exposure, only patients with suspected or clinically confirmed BFR received CT follow-up. To exclude the bias of pure clinical follow-up in patients with indication for BFR, a sensitivity analysis was conducted considering only CT follow-up. A p value of $<0.05$ was considered statistically significant. Statistical analysis was performed using standard commercial software (IBM SPSS Statistics for Windows, version 21.0, IBM Corp.).

\section{Ethics}

Approval was granted by the local ethics committee (Kantonale Ethikkommission Bern, Switzerland).

\section{Results \\ Patient Characteristics}

During June 2003 to August 2015 a total of 183 patients (age range 4-81 years) who received AC after DC were assessed for study eligibility. A total of 25 patients (13.7\%) did not meet the eligibility criteria; 22 of these patients had been lost to follow-up after AC and 3 patients had died before any follow-up (Fig. 2).

The baseline characteristics of the 158 eligible patients are summarized in Table 1. The median time between DC and $\mathrm{AC}$ was 70 days (interquartile range [IQR] 46-103.25 days), and the median follow-up time was 2.2 years $(95 \%$ CI 1.9-2.5 years). The patients' mean age at the time of AC was 43.6 years (IQR 31.5-56 years), and 101 (63.9\%) were male. The most common diagnosis resulting in DC was traumatic brain injury (TBI, $\mathrm{n}=62,39.2 \%$ ) followed by cerebrovascular ischemia (CVI, $\mathrm{n}=35,22.2 \%)$ and intracerebral hemorrhage (ICH, $\mathrm{n}=25,15.8 \%$ ). Twentyeight patients (17.7\%) received a ventriculoperitoneal (VP) 
TABLE 1. Baseline patient characteristics

\begin{tabular}{|c|c|c|c|c|c|}
\hline Variable & All Pts $(n=158)$ & Pts w/o BFR $(n=111)$ & Pts w/ BFR $(n=47)$ & RR/Difference* $(95 \%$ Cl) & $\mathrm{p}$ Value \\
\hline Age in yrs, mean & $43.6 \pm 16.3$ & $45.3 \pm 16.0$ & $39.5 \pm 16.3$ & $5.84(0.31-11.38)$ & 0.039 \\
\hline Male sex, $\mathrm{n}(\%)$ & $101(63.9 \%)$ & $73(65.8 \%)$ & $28(59.6 \%)$ & $0.83(0.51-1.35)$ & 0.474 \\
\hline \multicolumn{6}{|l|}{ Admission diagnosis, $\mathrm{n}(\%)$} \\
\hline $\mathrm{ICH}$ & $25(15.8 \%)$ & $23(20.7 \%)$ & $2(4.3 \%)$ & $0.24(0.06-0.91)$ & 0.008 \\
\hline SAH & $17(10.8 \%)$ & $8(7.2 \%)$ & $9(19.1 \%)$ & $1.96(1.16-3.32)$ & 0.046 \\
\hline $\mathrm{CVI}$ & $35(22.2 \%)$ & $28(25.2 \%)$ & $7(14.9 \%)$ & $0.62(0.30-1.25)$ & 0.209 \\
\hline TBI & $62(39.2 \%)$ & $41(36.9 \%)$ & $21(44.7 \%)$ & $1.25(0.78-2.02)$ & 0.378 \\
\hline $\mathrm{SDH}$ & $6(3.8 \%)$ & $4(3.6 \%)$ & $2(4.3 \%)$ & $1.13(0.35-3.58)$ & 1.000 \\
\hline Cerebral infection & $4(2.5 \%)$ & $2(1.8 \%)$ & $2(4.3 \%)$ & $1.71(0.62-4.70)$ & 0.583 \\
\hline Miscellaneous & $9(5.7 \%)$ & $5(4.5 \%)$ & $4(8.5 \%)$ & $0.65(0.30-1.41)$ & 0.452 \\
\hline VP shunt, n (\%) & $28(17.7 \%)$ & $22(19.8 \%)$ & $6(12.8 \%)$ & $0.68(0.32-1.44)$ & 0.365 \\
\hline Time from $D C$ to $A C$ in mos, mean & $2.7 \pm 1.7$ & $2.6 \pm 1.5$ & $2.8 \pm 2.1$ & $0.13(-0.46$ to 0.72$)$ & 0.666 \\
\hline \multicolumn{6}{|l|}{ Medical conditions, $\mathrm{n}(\%)$} \\
\hline Arterial hypertension & $68(43.0 \%)$ & $56(50.5 \%)$ & $12(25.5 \%)$ & $0.45(0.26-0.81)$ & 0.005 \\
\hline Diabetes mellitus & $10(6.3 \%)$ & $8(7.2 \%)$ & $2(4.3 \%)$ & $0.66(0.19-2.33)$ & 0.724 \\
\hline \multicolumn{6}{|l|}{ Antihypertensive therapy, $\mathrm{n}(\%)$} \\
\hline ACEI & $57(36.1 \%)$ & $50(45 \%)$ & $7(14.9 \%)$ & $0.31(0.15-0.65)$ & $<0.001$ \\
\hline Other antihypertensive drugs & $46(29.1 \%)$ & $37(33.3 \%)$ & $9(19.1 \%)$ & $0.58(0.30-1.09)$ & 0.086 \\
\hline Nicotine consumption & $36(22.8 \%)$ & $25(22.5 \%)$ & $11(23.4 \%)$ & $1.02(0.79-1.3)$ & 1.000 \\
\hline Size in $\mathrm{cm}^{2}$, mean & $110.1 \pm 22.4$ & $112.5 \pm 2.1$ & $104.9 \pm 2.6$ & $7.6(-0.10$ to 15.35$)$ & 0.053 \\
\hline$\geq 2$ fragments, $n(\%) \dagger$ & $43(29.3 \%)$ & $26(25.5 \%)$ & $17(37.8 \%)$ & $1.47(0.90-2.39)$ & 0.096 \\
\hline
\end{tabular}

Pts = patients; $\mathrm{SDH}=$ subdural hemorrhage.

Continuous values are depicted as means $\pm S D$, discrete values as their absolute number of observations $(n)$ and the percentage of the respective group; $p$ values are from 2-sample t-tests for continuous variables and Fisher's exact tests for categorical variables.

* The relative risk is presented for categorical data and the difference in the means for continuous data.

$\dagger$ Total $n=147$, with BFR = 45, without BFR = 102 .

shunt around the time of DC. Fixation methods applied were titanium clamps in 7 patients (4.4\%), titanium plates and screws in 150 patients $(93.8 \%)$, and sutures in 1 patient $(0.6 \%)$. Arterial hypertension was documented in 68 patients (43\%). In $22(32.4 \%)$ of these 68 patients it was newly diagnosed at DC; 41 (60.3\%) had documented arterial hypertension in the admissions report for $\mathrm{DC}$ or older medical reports, and 5 patients (7.4\%) were first recorded to have arterial hypertension at AC. A prescription for an ACEI was recorded for 57 of the hypertensive patients (36.1\%) during their stay for $\mathrm{AC}$ or at later follow-up visits. Of the 101 patients who were not treated with an ACEI, 15 (14.9\%) had a recorded diagnosis of arterial hypertension. Seven (14.9\%) (see Fig. 2 and Table 3) of the patients who were prescribed an ACEI developed BFR.

A total of 47 patients (29.7\%) were clinically or radiologically diagnosed with BFR. Of the patients with BFR, 2 declined revision surgery despite their neurosurgeons' recommendations. Seven patients $(4.4 \%)$ developed a wound infection after AC, of which none developed BFR. Two patients had surgical revision reasons other than BFR. One patient had severe dislocation of the autologous bone flap 9 years after $\mathrm{AC}$, and 1 patient had an intracranial empyema 1 year and 8 months after $\mathrm{AC}$. These patients were defined as having no BFR and were censored at the time of surgical revision.

\section{Univariate Analysis}

Univariate comparison showed that patients with BFR were younger (mean age 39.5 vs 45.3 years, $p=0.039$ ), less likely to have arterial hypertension (relative risk [RR] $0.45,95 \%$ CI $0.26-0.81, \mathrm{p}=0.005)$, and less likely to be treated with ACEIs (RR 0.31, 95\% CI $0.15-0.65$, p $<0.001$ ), as well as less (RR 0.31) likely to have had an ICH (RR 0.24, 95\% CI 0.06-0.91, p = 0.008) and more (RR 1.96) frequently subarachnoid hemorrhage (SAH, RR $1.96,95 \%$ CI 1.16-3.32, $\mathrm{p}=0.046)$ (Table 1).

Univariate Kaplan-Meier analysis revealed that ACEI therapy (2-year EFP [ \pm standard error $] 83.8 \% \pm 6.1 \%$ vs $63.9 \% \pm 5.6 \%, \mathrm{p}=0.02)$ and VP shunt placement (2-year EFP $86.9 \% \pm 7.1 \%$ vs $66 \% \pm 5.0 \%, p=0.024)$ were associated with a lower probability of BFR (Table 2, Fig. 3).

\section{Cox Regression Analysis}

According to multiple Cox regression analysis ACEI treatment was associated with a lower risk for BFR (HR $0.293,95 \%$ CI $0.112-0.764, p=0.012$ ), as were VP shunt placement (HR 0.278, 95\% CI 0.106-0.724, $\mathrm{p}=0.009)$ and male sex (HR 0.500, 95\% CI 0.258-0.969, p = 0.040) (Fig. 4). Fragmentation of the bone flap was associated with a higher rate of BFR (HR 1.920, 95\% CI 1.061-3.477, $\mathrm{p}=$ 0.031). 
TABLE 2. Results of univariate Kaplan-Meier analysis with logrank test

\begin{tabular}{|c|c|c|c|c|}
\hline Variable & $\begin{array}{c}\text { 2-yr EFP* } \\
(\%)\end{array}$ & $\begin{array}{c}\text { mTTE } \\
\text { (yrs) }\end{array}$ & $\begin{array}{l}\text { mTTE, } \\
95 \% \mathrm{Cl}\end{array}$ & $\begin{array}{c}p \\
\text { Value }\end{array}$ \\
\hline Age in yrs & & & & 0.632 \\
\hline $0-20$ & $55.6 \pm 11.7$ & 4.2 & $0.0-8.8$ & \\
\hline $21-40$ & $65.7 \pm 8.5$ & 3.8 & $2.1-5.5$ & \\
\hline $41-60$ & $74.9 \pm 6.6$ & 3.7 & $2.4-5.0$ & \\
\hline $61-80$ & $79.7 \pm 9.1$ & NR & NR & \\
\hline Sex & & & & 0.075 \\
\hline Male & $74.1 \pm 5.1$ & 3.9 & $3.5-4.4$ & \\
\hline Female & $63.4 \pm 7.6$ & 2.7 & $2.3-3.1$ & \\
\hline VP shunt & & & & 0.024 \\
\hline Yes & $86.9 \pm 7.1$ & 4.2 & NR & \\
\hline No & $66.0 \pm 5.0$ & 3.6 & $2.5-4.7$ & \\
\hline Time from $D C$ to $A C$ in mos & & & & 0.551 \\
\hline$\leq 2$ & $72.9 \pm 6.7$ & 4.2 & $2.0-6.4$ & \\
\hline $2.1-4$ & $64.0 \pm 6.8$ & 3.4 & $2.1-4.8$ & \\
\hline $4.1-6$ & $72.9 \pm 13.5$ & 3.9 & NR & \\
\hline$>6.1$ & $90.0 \pm 9.5$ & 3.6 & $0.0-8.1$ & \\
\hline ACEI & & & & 0.02 \\
\hline Yes & $83.8 \pm 6.1$ & NR & NR & \\
\hline No & $63.9 \pm 5.6$ & 3.6 & $2.4-4.9$ & \\
\hline Bone flap size in $\mathrm{cm}^{2}$ & & & & 0.52 \\
\hline$\leq 70$ & $38.1 \pm 19.9$ & 1.9 & $0.1-3.7$ & \\
\hline $71-90$ & $90.9 \pm 8.7$ & 3.7 & $2.6-4.8$ & \\
\hline $91-110$ & $68.8 \pm 9.2$ & 3.9 & $2.5-5.4$ & \\
\hline$\geq 110$ & $66.3 \pm 6.0$ & 3.4 & NR & \\
\hline Fragments & & & & 0.488 \\
\hline$\geq 2$ & $65.3 \pm 7.8$ & 5.5 & $1.8-9.2$ & \\
\hline$<2$ & $69.1 \pm 5.6$ & 3.8 & $3.6-4.8$ & \\
\hline
\end{tabular}

2-yr EFP = 2-year event free probability; $\mathrm{mTTE}=$ median time to event; $\mathrm{NR}=$ not reached.

* Presented with standard error.

A sensitivity analysis considering only CT follow-up and omitting clinical follow-up data continued to show a reduced risk for BFR in patients with ACEIs (HR 0.299, p $=0.01$ ), as well as an elevated risk in patients with multiple fragmentation of the bone flap (HR 1.794, $\mathrm{p}=0.042$ ).

\section{Discussion}

\section{Definition of Bone Flap Resorption}

As of this writing, there has been no consensus on a definition for the term "bone flap resorption" (BFR). Ewald et al. ${ }^{9}$ and Dünisch et al. ${ }^{8}$ defined a type II bone flap necrosis as a circumscribed or complete lysis of both the tabula interna and the tabula externa with the requirement of surgical revision. Stieglitz et al. ${ }^{35}$ categorized BFR using a scoring system, with major resorption requiring a second surgery. We limited the definition of BFR to the indication for revision surgery. In our study, 47 patients (29.7\%) were diagnosed with BFR, which appears to be in line with rates previously reported in the literature (Table 3 ).

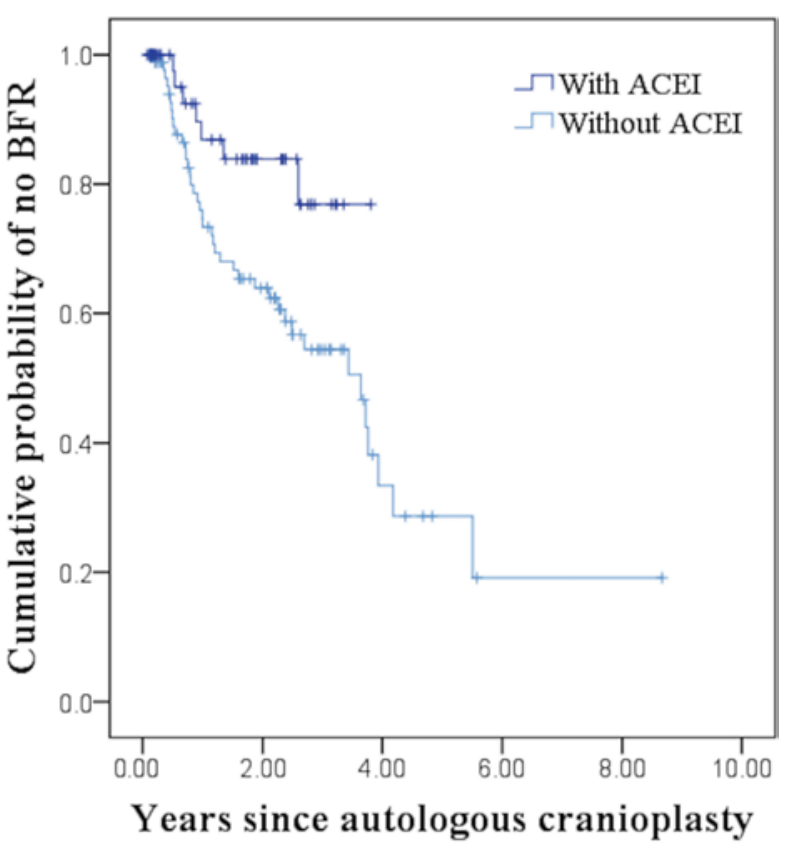

No. at risk

$\begin{array}{llllll}57 & 51 & 50 & & \\ & 101 & 73 & 63 & 61 & 61\end{array}$

FIG. 3. Kaplan-Meier analysis of patients with and without ACEI treatment and number of patients at risk after each time interval. Tick marks indicate censored events.

\section{Arterial Hypertension and BFR}

Arterial hypertension was a frequent comorbidity in our study (affecting $43 \%$ of patients, with $97.1 \%$ of these hypertensive patients receiving antihypertensive medication) because hypertensive patients have a severely heightened risk for cerebrovascular incidents such as CVI or ICH. ${ }^{1,23}$ Analysis of baseline characteristics showed that a majority of the patients with BFR were admitted with TBI $(\mathrm{n}=21,44.7 \%)$ and SAH $(\mathrm{n}=9,19.1 \%)$, and that the majority of patients without BFR were admitted due to TBI $(\mathrm{n}=$ $41,36.9 \%)$ or CVI $(n=28,25.2 \%)$. More patients suffered from ICH than from SAH $(n=25,15.8 \%$ vs $n=17,10.8 \%)$. In a prospective study involving elderly females, Cappuccio et al. ${ }^{6}$ showed that hypertension is associated with an abnormal calcium metabolism. It leads to increased urinary calcium excretion, secondary activation of the parathyroid gland, and increased calcium mobilization from bone. In our study, 68 patients had a diagnosis of arterial hypertension, and $12(17.6 \%)$ of these patients developed BFR. Sixty-six (97.1\%) of the 68 patients with arterial hypertension received antihypertensive medication, and 57 (83.8\%) of these 68 received an ACEI.

However, we cannot assume that the possible benefit of ACEI therapy with respect to development of BFR is based solely on normalization of blood pressure. According to the literature, not all antihypertensive drugs beneficially affect osteoporosis and bone mineralization, as they differ in the way they work to reduce blood pressure. ${ }^{19,38}$ Previous findings suggest a beneficial effect of 


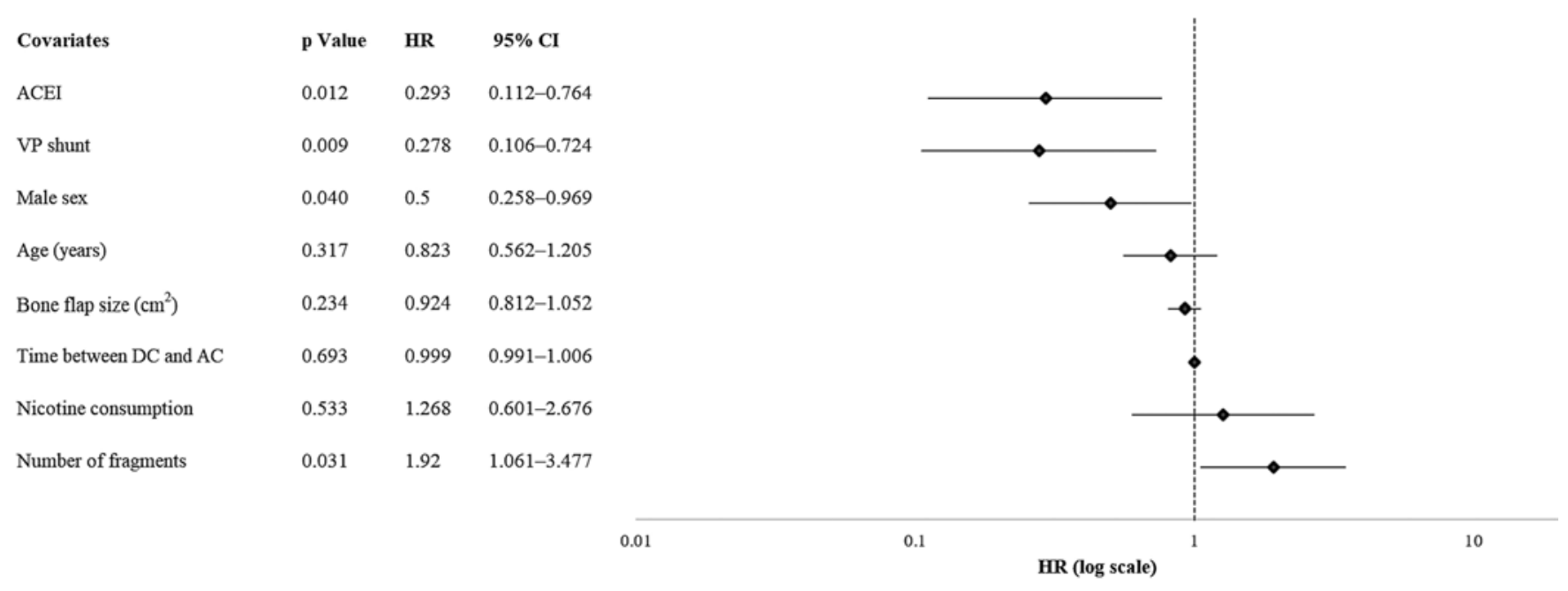

FIG. 4. Results and plot of hazard ratios from a multiple Cox regression analysis on a logarithmic scale.

ACEI therapy on bone preservation by direct alteration of the RAAS. ${ }^{12,16}$

\section{The Renin-Angiotensin-Aldosterone System and Bone Metabolism}

In recent years, multiple studies conducted in orthopedic, osteoporosis, and endocrinology research have associated ACEIs with a beneficial effect on bone preservation and bone healing. ${ }^{26,28,31,34,39}$ In animal studies, activation of the renin-angiotensin-aldosterone system (RAAS), a system that regulates blood volume and pressure through multiple hormones and enzymes systemically and locally, seems to induce osteoporosis, ${ }^{2}$ which was attenuated by ACEI administration. ${ }^{34}$ Furthermore, it has been possible to increase bone resorption and decrease bone mineral density by administration of angiotensin II in a mouse model, ${ }^{2}$ while local injection of ACEI into the area of tibial fractures has resulted in improved bone healing in a rat model. ${ }^{39}$ In human studies, a 1-hour infusion of angiotensin II, alone or in combination with human parathyroid hormone (PTH), has been shown to inhibit RAAS and calcium metabolism, ${ }^{13}$ whereas ACEI therapy was associated with an increased bone mass ${ }^{26}$ and a decreased fracture risk. ${ }^{13,28,31,37}$

Previous studies have explained these effects by showing that angiotensin II indirectly stimulates osteoclast formation, ${ }^{2}$ leads to decreased ionic calcium and increased PTH levels, ${ }^{13}$ and directly affects local tissue-specific RAAS also found within bone tissue. ${ }^{12,16}$ Administration of an ACEI prevents the enzymatic conversion of angiotensin I into angiotensin II, thus preventing the catabolic effect of angiotensin II, thus resulting in decreased bone resorption. Furthermore, ACEIs have been shown to increase bone mass in hypertensive women with a specific polymorphism of the $A C E$ gene due to a stronger inhibitory effect by the ACEI and further decrease of angiotensin II levels. ${ }^{26}$

Of the 68 (Table 1) hypertensive patients in our study, 57 (84\%) were following a regimen of ACEI therapy. We identified these patients as having a lower rate of BFR.

Our results are in line with findings in the literature, showing how ACEIs can positively affect osteogenesis by alteration of the RAAS in hypertensive patients. This implicates a potential preventive measure against BFR, which could be offered to patients undergoing AC. However, our investigation was limited to a prescription for an ACEI in patients with a known arterial hypertension. Their effects on BFR in normotensive patients therefore remain unclear. For future studies, we recommend considering all drugs acting on the RAAS and their potential effects on bone metabolism, as well as investigating the effects of ACEIs on BFR in normotensive patients.

\section{Sex, VP Shunts, and Bone Fragmentation}

In our analysis, we found male sex to be associated with lower BFR rates. Previous studies did not identify patient sex as a risk factor for BFR in pediatric and mixed cohorts. ${ }^{4,8}$ However, prior studies suggest an altered bone metabolism in postmenopausal women due to changes in estrogen levels affecting bone metabolism (e.g., resulting in lower bone mineral density ${ }^{11}$ or complications in the healing of fractures such as clavicular or femoral neck fractures ${ }^{24,29}$ ).

Additionally, our analysis found VP shunt placement to be associated with lower BFR rates. In previous studies, shunt-dependent hydrocephalus has been reported to be a risk factor for BFR, ${ }^{4,22,25}$ the reason for this however is not established. Overall, the impact of hydrocephalus and VP shunts on BFR rates remains unclear.

Increasing fragmentation of the bone flap was associated with higher BFR rates, confirming results found in previous reports. ${ }^{5,8,21,33}$ It has been theorized that fragmentation leads to a nutritional deficit of the bone flap ${ }^{8}$ and disturbance of later angiogenesis and the survival of the graft. $^{5}$

\section{Limitations}

Given that this was a single-institution study, our cohort size and event numbers were limited. Because our institutional protocol only required a 6 -week postoperative fol- 
TABLE 3. Review of resorption rates found in the literature, as well as mean or median age and follow-up documented

\begin{tabular}{lccc}
\hline \multicolumn{1}{c}{ Authors \& Year } & $\begin{array}{c}\text { Total BFR } \\
\text { Rate (\%) }\end{array}$ & $\begin{array}{c}\text { Follow-Up } \\
(\text { mos) }\end{array}$ & $\begin{array}{c}\text { Age } \\
(\mathrm{yrs})^{*}\end{array}$ \\
\hline Bowers et al., 2013 & 50 & 37.9 & 6.2 \\
\hline Brommeland et al., 2015 & 19.7 & 9.9 & 31 \\
\hline Dünisch et al., 2013 & 22.8 & 11 & 48.6 \\
\hline Ewald et al., 2014 & 22.8 & 9 & 54.3 \\
\hline Honeybul \& Ho, 2016 & 20.9 & $\mathrm{NA}$ & 36 \\
\hline Martin et al., 2014 & 81.8 & 83 & 4.9 vs 17.4† \\
\hline Mracek et al., 2015 & 20 & 11 & 49 \\
\hline Pechmann et al., 2015 & 50 & 29.4 & 8.5 \\
\hline Piedra et al., 2013 & 17 & 24.2 & 29.5 \\
\hline Schoekler \& Trummer, 2014 & 8 & NA $\ddagger$ & 46 \\
\hline Schuss et al., 2013 & 4 & 45 & 45 \\
\hline Stieglitz et al., 2015 & 30.4 & 21.6 & 46.2 \\
\hline Present study overall & 29.7 & 26.1 & 43.6 \\
\hline w/ ACEl & 12.3 & 20.5 & 53.1 \\
\hline w/o ACEl & 39.6 & 29.2 & 38.2 \\
\hline
\end{tabular}

$\mathrm{NA}=$ not available

* Mean or median values, as documented in cited source.

$†$ Analysis of 2 patient subgroups (age $<15$ years vs $15-18$ years).

$\ddagger$ Routine follow-up was performed 6 months after bone flap reimplantation.

low-up visit, a minority of patients did not receive further follow-up evaluations. This may be because they or their caregivers did not consider additional follow-up necessary, or it may be due to other unknown reasons. Intraoperative placement of multiple perforations in the bone flap and the fixation method were not standardized. Neither were duration, dosage, or combination of drug therapy. In the literature an elevated risk for osteoporosis and fractures have been found to be associated with many medical and metabolic factors (e.g., increasing age, steroid therapy, hormonal factors including menopause, amenorrhea, hyperthyroidism, hyperadrenocorticism and hypogonadism) as well as lifestyle factors, such as low physical activity, nicotine or alcohol consumption, low body weight, or low dietary calcium and vitamin D intake. ${ }^{7}$ In recent years interest has risen as to the use of osteoinductive factors such as bone morphogenetic proteins (BMPs), which have been applied in orthopedic surgery to improve bone healing and enhance spinal fusion. ${ }^{20}$ However, to our knowledge BMPs have not been applied in autologous cranioplasty. Apart from patient age and nicotine consumption, which were not significant in our analysis, we did not assess any of these factors.

\section{Conclusions}

ACEI therapy appears to decrease the risk of BFR after $\mathrm{AC}$ in hypertensive patients (76\% relative risk reduction). This finding is in line with previous reports on the positive influence of ACEIs on bone healing and preservation. ACEI therapy may thus be considered as the antihypertensive treatment of choice in patients who have undergone AC. Further analysis of the association between ACEI and BFR development is needed and will be evaluated in the Swiss Prospective Autologous Bone Flap Resorption Study (SPARS), a multicenter prospective trial. ${ }^{36}$

\section{References}

1. Ariesen MJ, Claus SP, Rinkel GJ, Algra A: Risk factors for intracerebral hemorrhage in the general population: a systematic review. Stroke 34:2060-2065, 2003

2. Asaba Y, Ito M, Fumoto T, Watanabe K, Fukuhara R, Takeshita S, et al: Activation of renin-angiotensin system induces osteoporosis independently of hypertension. J Bone Miner Res 24:241-250, 2009

3. Ashayeri K, M Jackson E, Huang J, Brem H, R Gordon C: Syndrome of the trephined: a systematic review. Neurosurgery 79:525-534, 2016

4. Bowers CA, Riva-Cambrin J, Hertzler DA II, Walker ML: Risk factors and rates of bone flap resorption in pediatric patients after decompressive craniectomy for traumatic brain injury. J Neurosurg Pediatr 11:526-532, 2013

5. Brommeland T, Rydning PN, Pripp AH, Helseth E: Cranioplasty complications and risk factors associated with bone flap resorption. Scand J Trauma Resusc Emerg Med 23:75, 2015

6. Cappuccio FP, Meilahn E, Zmuda JM, Cauley JA: High blood pressure and bone-mineral loss in elderly white women: a prospective study. Lancet 354:971-975, 1999

7. Dontas IA, Yiannakopoulos CK: Risk factors and prevention of osteoporosis-related fractures. J Musculoskelet Neuronal Interact 7:268-272, 2007

8. Dünisch P, Walter J, Sakr Y, Kalff R, Waschke A, Ewald C: Risk factors of aseptic bone resorption: a study after autologous bone flap reinsertion due to decompressive craniotomy. J Neurosurg 118:1141-1147, 2013

9. Ewald C, Duenisch P, Walter J, Götz T, Witte OW, Kalff R, et al: Bone flap necrosis after decompressive hemicraniectomy for malignant middle cerebral artery infarction. Neurocrit Care 20:91-97, 2014

10. Feroze AH, Walmsley GG, Choudhri O, Lorenz HP, Grant GA, Edwards MS: Evolution of cranioplasty techniques in neurosurgery: historical review, pediatric considerations, and current trends. J Neurosurg 123:1098-1107, 2015

11. Garnero P, Sornay-Rendu E, Chapuy MC, Delmas PD: Increased bone turnover in late postmenopausal women is a major determinant of osteoporosis. J Bone Miner Res 11:337-349, 1996

12. Gebru Y, Diao TY, Pan H, Mukwaya E, Zhang Y: Potential of RAS inhibition to improve metabolic bone disorders. BioMed Res Int 2013:932691, 2013

13. Grant FD, Mandel SJ, Brown EM, Williams GH, Seely EW: Interrelationships between the renin-angiotensin-aldosterone and calcium homeostatic systems. J Clin Endocrinol Metab 75:988-992, 1992

14. Güresir E, Vatter H, Schuss P, Oszvald A, Raabe A, Seifert V, et al: Rapid closure technique in decompressive craniectomy. J Neurosurg 114:954-960, 2011

15. Harris PA, Taylor R, Thielke R, Payne J, Gonzalez N, Conde JG: Research electronic data capture (REDCap)--a metadatadriven methodology and workflow process for providing translational research informatics support. J Biomed Inform 42:377-381, 2009

16. Hatton R, Stimpel M, Chambers TJ: Angiotensin II is generated from angiotensin I by bone cells and stimulates osteoclastic bone resorption in vitro. J Endocrinol 152:5-10, 1997

17. Honeybul S, Ho KM: Cranioplasty: morbidity and failure. $\mathbf{B r}$ J Neurosurg 30:523-528, 2016

18. Kurland DB, Khaladj-Ghom A, Stokum JA, Carusillo B, Karimy JK, Gerzanich V, et al: Complications associated with decompressive craniectomy: a systematic review. Neurocrit Care 23:292-304, 2015 
19. Lykissas M, Gkiatas I: Use of recombinant human bone morphogenetic protein-2 in spine surgery. World J Orthop 8:531-535, 2017

20. Lynn H, Kwok T, Wong SY, Woo J, Leung PC: Angiotensin converting enzyme inhibitor use is associated with higher bone mineral density in elderly Chinese. Bone 38:584-588, 2006

21. Martin KD, Franz B, Kirsch M, Polanski W, von der Hagen M, Schackert G, et al: Autologous bone flap cranioplasty following decompressive craniectomy is combined with a high complication rate in pediatric traumatic brain injury patients. Acta Neurochir (Wien) 156:813-824, 2014

22. Mracek J, Hommerova J, Mork J, Richtr P, Priban V: Complications of cranioplasty using a bone flap sterilised by autoclaving following decompressive craniectomy. Acta Neurochir (Wien) 157:501-506, 2015

23. O'Donnell MJ, Xavier D, Liu L, Zhang H, Chin SL, RaoMelacini P, et al: Risk factors for ischaemic and intracerebral haemorrhagic stroke in 22 countries (the INTERSTROKE study): a case-control study. Lancet 376:112-123, 2010

24. Parker MJ, Raghavan R, Gurusamy K: Incidence of fracturehealing complications after femoral neck fractures. Clin Orthop Relat Res 458:175-179, 2007

25. Pechmann A, Anastasopoulos C, Korinthenberg R, van Velthoven-Wurster V, Kirschner J: Decompressive craniectomy after severe traumatic brain injury in children: complications and outcome. Neuropediatrics 46:5-12, 2015

26. Pérez-Castrillón JL, Silva J, Justo I, Sanz A, Martín-Luquero $\mathrm{M}$, Igea R, et al: Effect of quinapril, quinapril-hydrochlorothiazide, and enalapril on the bone mass of hypertensive subjects: relationship with angiotensin converting enzyme polymorphisms. Am J Hypertens 16:453-459, 2003

27. Piedra MP, Ragel BT, Dogan A, Coppa ND, Delashaw JB: Timing of cranioplasty after decompressive craniectomy for ischemic or hemorrhagic stroke. J Neurosurg 118:109-114, 2013

28. Rejnmark L, Vestergaard P, Mosekilde L: Treatment with beta-blockers, ACE inhibitors, and calcium-channel blockers is associated with a reduced fracture risk: a nationwide casecontrol study. J Hypertens 24:581-589, 2006

29. Robinson CM, Court-Brown CM, McQueen MM, Wakefield AE: Estimating the risk of nonunion following nonoperative treatment of a clavicular fracture. J Bone Joint Surg Am 86-A:1359-1365, 2004

30. Schemper M, Smith TL: A note on quantifying follow-up in studies of failure time. Control Clin Trials 17:343-346, 1996

31. Schlienger RG, Kraenzlin ME, Jick SS, Meier CR: Use of beta-blockers and risk of fractures. JAMA 292:1326-1332, 2004

32. Schoekler B, Trummer M: Prediction parameters of bone flap resorption following cranioplasty with autologous bone. Clin Neurol Neurosurg 120:64-67, 2014

33. Schuss P, Vatter H, Oszvald A, Marquardt G, Imöhl L, Seifert $\mathrm{V}$, et al: Bone flap resorption: risk factors for the development of a long-term complication following cranioplasty after decompressive craniectomy. J Neurotrauma 30:91-95, 2013

34. Shimizu H, Nakagami H, Osako MK, Nakagami F, Kunugiza Y, Tomita T, et al: Prevention of osteoporosis by angiotensin- converting enzyme inhibitor in spontaneous hypertensive rats. Hypertens Res 32:786-790, 2009

35. Stieglitz LH: The Swiss Prospective Autologous Bone Flap Resorption Study (SPARS): a multicentric approach to quantify the complication rate after reimplantation of autologous cryoconserved bone flaps. Acta Neurochir (Wien) 157:1001, 2015 (Letter)

36. Stieglitz LH, Fung C, Murek M, Fichtner J, Raabe A, Beck $\mathrm{J}$ : What happens to the bone flap? Long-term outcome after reimplantation of cryoconserved bone flaps in a consecutive series of 92 patients. Acta Neurochir (Wien) 157:275-280, 2015

37. Wiens M, Etminan M, Gill SS, Takkouche B: Effects of antihypertensive drug treatments on fracture outcomes: a metaanalysis of observational studies. J Intern Med 260:350362,2006

38. Yamamoto S, Kido R, Onishi Y, Fukuma S, Akizawa T, Fukagawa M, et al: Use of renin-angiotensin system inhibitors is associated with reduction of fracture risk in hemodialysis patients. PLoS One 10:e0122691, 2015

39. Zhao X, Wu ZX, Zhang Y, Gao MX, Yan YB, Cao PC, et al: Locally administrated perindopril improves healing in an ovariectomized rat tibial osteotomy model. PLoS One 7:e33228, 2012

\section{Disclosures}

Dr. Shucht reports an ownership interest in Trustedoctor.

\section{Author Contributions}

Conception and design: Schütz, Murek, Bernasconi, Schucht. Acquisition of data: Schütz, Stieglitz. Analysis and interpretation of data: Schütz, Murek, Bernasconi. Drafting the article: Schütz, Murek, Schucht. Critically revising the article: Murek, Stieglitz, Bernasconi, Vulcu, Beck, Raabe, Schucht. Reviewed submitted version of manuscript: Murek, Stieglitz, Bernasconi, Vulcu, Beck, Raabe, Schucht. Statistical analysis: Schütz, Murek, Bernasconi. Administrative/technical/material support: Schütz. Study supervision: Beck, Schucht.

\section{Supplemental Information \\ Previous Presentations}

Portions of this work were presented in poster form at the European Association for Neurosurgical Societies (EANS) Congress 2016 in Athens, Greece, September 4-8, 2016, and the American Association for Neurological Surgeons (AANS) annual scientific meeting in Los Angeles, California, April 22-26, 2017. Oral presentations were given at the SFCNS Congress in Basel, Switzerland, September 28, 2016, and at the WFNS XVI World Congress of Neurosurgery in Istanbul, Turkey, August 24, 2017.

\section{Correspondence}

Alessa Schütz: Bern University Hospital, Bern, Switzerland. alessa.schuetz@insel.ch. 